\title{
Activation of executioner caspases is a predictor of progression-free survival in glioblastoma patients: a systems medicine approach
}

\author{
ÁC Murphy ${ }^{1}$, B Weyhenmeyer ${ }^{1}$, J Schmid ${ }^{1}$, SM Kilbride ${ }^{1}$, M Rehm $^{1}$, HJ Huber ${ }^{1}$, C Senft ${ }^{2,3}$, J Weissenberger ${ }^{2}$, V Seifert ${ }^{3}$, M Dunst ${ }^{4}$, \\ M Mittelbronn ${ }^{4}$, D Kögel ${ }^{2}$, JHM Prehn ${ }^{1}$ and BM Murphy ${ }^{*, 1}$
}

Glioblastoma (GBM) is the most common and aggressive primary brain tumor in adults. GBM cells are highly resistant to apoptosis induced by antitumor drugs and radiotherapy resulting in cancer progression. We assessed whether a systems medicine approach, analysing the ability of tumor cells to execute apoptosis could be utilized to predict the response of GBM patients to treatment. Concentrations of the key proapoptotic proteins procaspase-3, procaspase-9, Smac and Apaf-1 and the antiapopotic protein XIAP were determined in a panel of GBM cell lines and GBM patient tumor resections. These values were used as input for APOPTO-CELL, a systems biological based mathematical model built to predict cellular susceptibility to undergo caspase activation. The modeling was capable of accurately distinguishing between GBM cells that die or survive in response to treatment with temozolomide in 10 of the 11 lines analysed. Importantly the results obtained using GBM patient samples show that APOPTO-CELL was capable of stratifying patients according to their progression-free survival times and predicted the ability of tumor cells to support caspase activation in 16 of the 21 GBM patients analysed. Calculating the susceptibility to apoptosis execution may be a potent tool in predicting GBM patient therapy responsiveness and may allow for the use of APOPTO-CELL in a clinical setting.

Cell Death and Disease (2013) 4, e629; doi:10.1038/cddis.2013.157; published online 16 May 2013

Subject Category: Experimental Medicine

Glioblastoma (GBM) is the most common and malignant primary brain tumor in adults. ${ }^{1,2}$ The current treatment regimen for GBM patients of surgical resection, radiotherapy and temozolomide (TMZ) chemotherapy, can prolong survival of patients for several months. ${ }^{3,4}$ However, the median survival rate for GBM patients remains dismal at $\sim 12$ months. ${ }^{5}$

It is widely recognized that one of the major contributors to the observed resistance of GBMs to chemotherapy and radiotherapy is the dysregulation of apoptotic pathways. ${ }^{6,7}$ Indeed, numerous survival proteins have been shown to be overexpressed in GBM, and attenuated levels of several proapoptotic proteins have been reported. ${ }^{8,9}$ However, systematic analyses examining how such complex alterations may impact on the ability of GBMs to successfully evade death signaling pathways have rarely been performed.

The anticancer treatment strategies of chemotherapy and radiotherapy typically attempt to engage the intrinsic or mitochondrial pathway of apoptosis to relay their death signals within their target population. ${ }^{10,11}$ Briefly, in this pathway upon mitochondrial outer membrane permeabilization (MOMP), cytochrome $c$ is released from the mitochondria into the cytosol, triggering formation of the apoptosome, which includes the apoptotic protease activating factor-1 (Apaf-1) and procaspase-9. ${ }^{12,13}$ Apoptosome formation enables activation of the initiator caspase, procaspase- 9 and subsequent activation of the executioner caspases, procaspase-3 and $-7 .^{13-15}$ Also released from the mitochondria is Smac/ DIABLO, which prevents the X-linked inhibitor of apoptosis protein (IAPs), XIAP from inhibiting its caspase targets. ${ }^{16,17}$ Once activated, the executioner caspases cleave key regulatory and structural proteins to produce most of the morphological and biochemical changes, characteristic of this type of cell death. ${ }^{13,15,18,19}$

As the proteins, Apaf-1, procaspase-9 and procaspase-3, Smac and XIAP are all critical players in the intrinsic

\footnotetext{
${ }^{1}$ Centre for Systems Medicine, Department of Physiology and Medical Physics, St. Stephen's Green, Dublin, Ireland; '2Department of Experimental Neurosurgery, Centre for Neurology and Neurosurgery, Johann Wolfgang Goethe University Hospital, Frankfurt, Germany; ${ }^{3}$ Department of Neurosurgery, Centre for Neurology and Neurosurgery, Johann Wolfgang Goethe University Hospital, Frankfurt, Germany and ${ }^{4}$ Institute of Neurology (Edinger Institute), Goethe-University, Frankfurt, Germany ${ }^{*}$ Corresponding author: BM Murphy, Centre for Systems Medicine, Department of Physiology and Medical Physics, York House, St. Stephen's Green, Dublin 2, Ireland. Tel: + 3531402 2119; Fax: 3531402 2447; E-mail: bronamurphy@ rcsi.ie

Keywords: glioblastoma; systems medicine; apoptosis

Abbreviations: Apaf-1, apoptotic protease activating factor-1; GBM, glioblastoma; MGMT, $0^{6}$-methylguanine-DNA methyltransferase; MOMP, mitochondrial outer membrane permeabilization; PARP, poly (ADP-ribose) polymerase; PFS, progression-free survival; Smac/DIABLO, second mitochondrial-derived activator of caspase/ direct inhibitor of apoptosis protein-binding protein with low pl; TMZ, temozolomide; TRAIL, tumor necrosis factor-related apoptosis-inducing ligand; XIAP, X-linked inhibitor of apoptosis protein; zVAD, n-benzyloxycarbonyl-Val-Ala-Asp(O-Me)

Received 15.2.13; revised 22.3.13; accepted 03.4.13; Edited by A Stephanou
} 
mitochondrial pathway of apoptosis, their expression profile has previously been analysed in GBM cell lines and tumor samples. Procaspase- 9 has been reported to be overexpressed in brain tumors ${ }^{20}$ while XIAP overexpression has been associated with poor prognosis. ${ }^{21}$ However, few studies have considered how the interactions of these proteins impact on the execution of apoptosis within GBMs and more importantly determined if the ability of a tumor cell to undergo apoptosis can subsequently be related to patient response to therapy. Therefore we asked if a systems medicine approach examining the expression of Apaf-1, procaspase- 9 and procaspase-3, Smac and XIAP could be utilized to determine GBM patient therapeutic response. We adopted the previously established mathematical systems model, APOPTO-CELL ${ }^{22,23}$ for our study. This model is based on the biochemical reactions between these critical components of the intrinsic mitochondrial pathway ${ }^{22}$ and enabled us to predict how the interactions between these apoptotic proteins impacted on apoptosis induction in GBM cell lines and more importantly GBM patient resections. Our study successfully demonstrates that a systems medicine approach analysing the interplay between these five key apoptotic proteins has clinical applicability and can be utilized to determine the progression-free survival (PFS) of GBM patients.

\section{Results}

Survival rates of individual GBM cell lines differ following treatment with TMZ. The response of GBM patients to TMZ can differ significantly. ${ }^{3}$ To examine this range of responses we treated our panel of GBM cell lines with TMZ. Our panel of cell lines consisted of both commercially available cell lines, A172, U87, U251, U343 and U373 and a cohort of lines derived from patient GBMs, including both primary (MZ-18, MZ-51, MZ-294, MZ-327) and recurrent (MZ-256, MZ-304) tumors. ${ }^{24}$ Cell survival was analysed using MTT cell viability assays (Figure 1). Following incubation with $150 \mu \mathrm{M} \mathrm{TMZ}$, a concentration, which has previously been demonstrated to correspond with the levels achieved in the serum of patients during treatment, ${ }^{25}$ one group of cells had survival rates of $90 \%$ or greater even after an incubation period of $120 \mathrm{~h}$ and consisted of $\mathrm{MZ}-18$

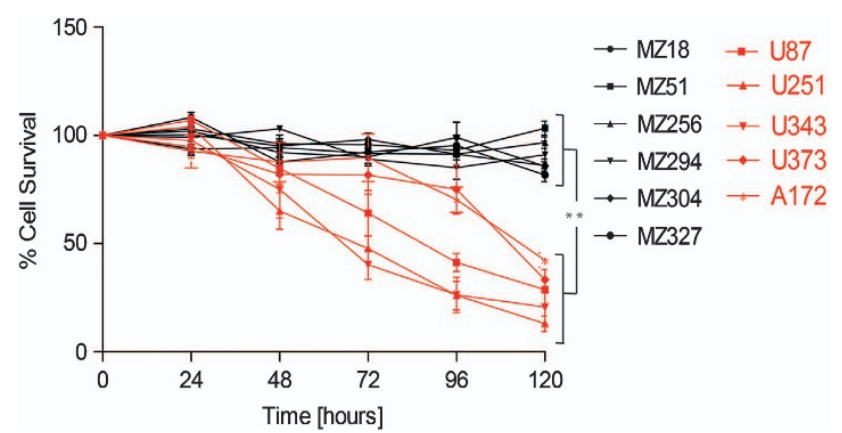

Figure 1 Treatment with TMZ significantly decreases cell survival in a subset of GBM cell lines. The panel of GBM cell lines was treated with TMZ (150 $\mu \mathrm{m})$ and a cell viability assay was carried out at $24,48,72,96$ and $120 \mathrm{~h}$ post-treatment. Two groups of cells were evident from this analysis: TMZ tolerant and TMZ sensitive. Data are expressed as mean \pm S.E.M. from three independent experiments (Student's $t$-test at end point, ${ }^{* \star} P<0.01$ )
(100\%), MZ-51 (93\%), MZ-256 (100\%), MZ-294 (93\%), MZ-304 (100\%) and MZ-327 (100\%; Figure 1). The second group of cells, which displayed significantly reduced survival rates $(P<0.01)$, all $<40 \%$ after $120 \mathrm{~h}$ exposure to $\mathrm{TMZ}$, consisted of U87 (30\%), U251 (10\%), U343 (8\%), U373 (39\%) and A172 (35\%; Figure 1). Thus, two distinct groups of cell lines displaying significantly differing sensitivities to TMZ were evident. Furthermore, when we treated this panel of cell lines with the broad-spectrum kinase inhibitor staurosporine, we also observed a similar pattern of response and could identify the same two distinct groups of cells (Supplementary Figure).

GBM cell lines display differential protein expression of apoptosis-related family members. We next sought to establish if the expression levels of key proteins in the mitochondrial apoptotic pathway could be utilized to predict the observed cellular response to treatment. Accordingly, we determined the amounts of five apoptosis-related family members, namely the proapoptotic proteins Apaf-1, procaspase-3, procaspase-9 and Smac and the antiapoptotic protein XIAP in our panel of 11 GBM cell lines using quantitative western blotting against HeLa cell extracts, in which concentrations of each protein have previously been determined (Figure 2a). ${ }^{22}$ The expression of Apaf- 1 and procaspase-9 were consistently lower in the GBM cell lines than in the HeLa control (Figures $2 b$ and $d$ ). Differential expression of procaspase-3 was observed in the GBM cell line lysates with some of the cell lines expressing greater levels than the HeLa cell line and others expressing lower levels (Figure 2c). Differential expression of Smac (Figure 2e) and XIAP (Figure 2f) was also noted in the GBM cell line lysates with the majority of samples expressing greater levels of Smac (Figure 2e) and varied levels of XIAP (Figure 2f) compared with the HeLa control. Statistical analysis of these protein expression levels relative to treatment outcome (Figure 1), indicated significantly higher expression of procaspase-3 in the cell lines that responded to $\mathrm{TMZ}$, than those which did not respond (Mann-Whitney U-test; $P=0.03$ ). No significant differences were identified in the expression of Apaf-1 $(P=0.93)$, procaspase-9 $(P=0.93), \operatorname{XIAP}(P=0.13)$ and Smac $(P=0.25)$.

\footnotetext{
A systems medicine approach, analysing apoptosomedependent caspase activation based on basal protein expression levels, predicts the ability of each GBM cell line to undergo apoptosis. To investigate if the abundance and the interaction of these apoptotic proteins could be utilized to calculate cell line response to apoptosis-inducing therapy we employed APOPTO-CELL, a systems biological mathematical model developed in our laboratory using $\mathrm{HeLa}$ cells. ${ }^{22}$ APOPTO-CELL is built on the input of quantitatively determined procaspase-3, procaspase-9, Smac, Apaf-1 and XIAP protein levels and its output is the prediction of cellular susceptibility to undergo caspase cleavage and activation.

The quantities of the apoptosis-related proteins expressed in each GBM cell line (Table 3A; Supplementary Material) were used as input for the model system and the time to achieve $80 \%$ substrate cleavage, a level previously determined to be required for apoptosis to proceed
} 

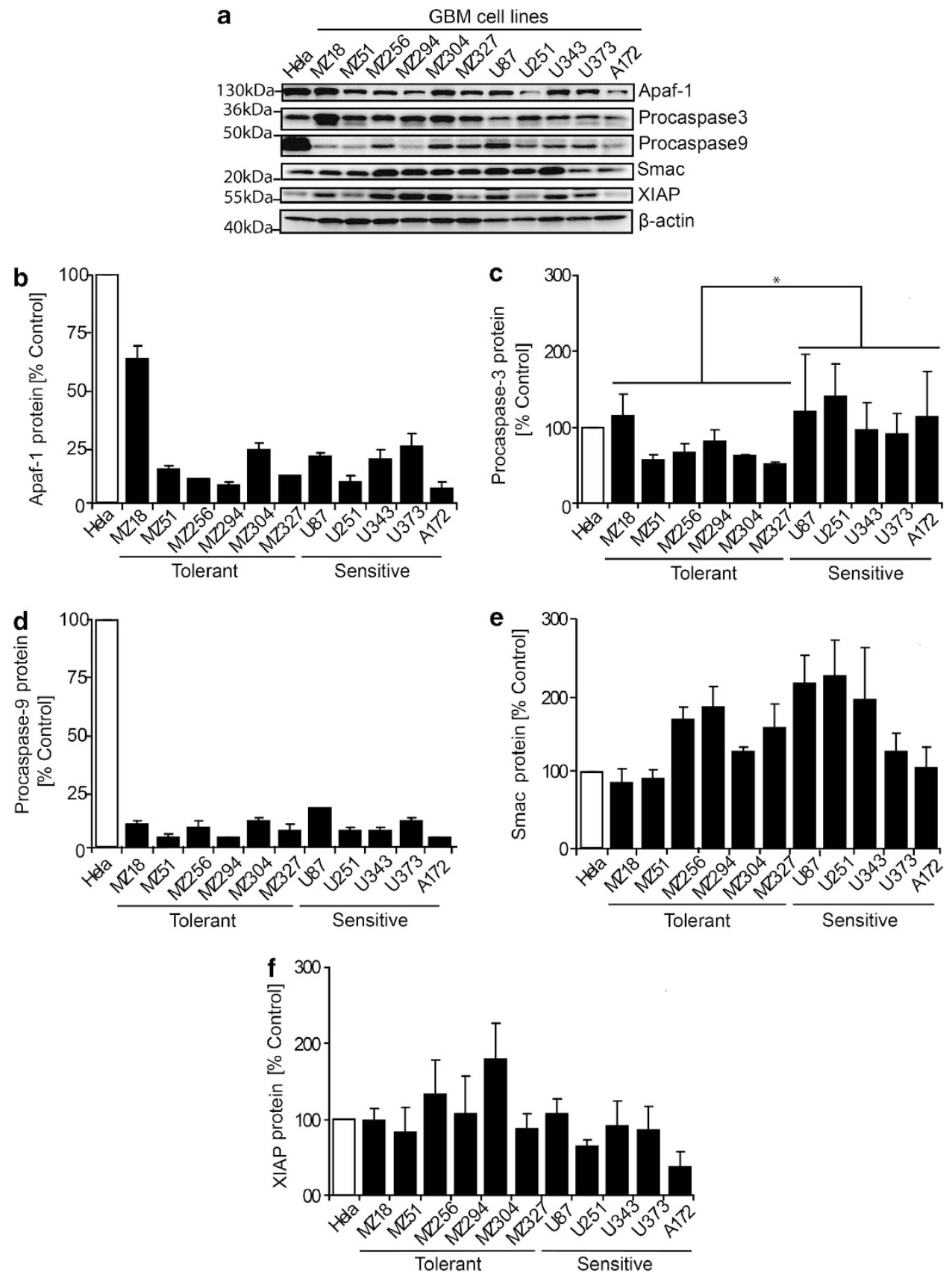

Figure 2 GBM cell lines differ in their basal protein expression levels of apoptotic proteins. Untreated whole-cell lysates of GBM cell lines and a HeLa cell line were analysed by western blotting. Western blots showing basal Apaf-1, procaspase-3, procaspase-9, Smac and XIAP expression levels in 11 GBM cell lines and the HeLa cell line; $\beta$-actin was used as a loading control (a). Densitometry analysis of basal protein expression levels of Apaf-1 (b), procaspase-3; Mann-Whitney U-test, ${ }^{*} P<0.05$ (c), procaspase-9 (d), Smac (e) and XIAP (f) in tolerant and sensitive GBM cell lines and the HeLa cell line (white bar). Protein expression levels are displayed as a percentage of HeLa protein expression (100\%). Data are expressed as means \pm S.E.M. from three independent experiments

efficiently, ${ }^{22}$ was calculated (Figures $3 a$ and b). The APOPTO-CELL output, accurately predicted the GBM cell line sensitivities (Figure 1) in 10 of the 11 cell lines, which corresponds to a predictive rate of $90.9 \%$. All of the cell lines we observed as sensitive to $\mathrm{TMZ}$ treatment were also correctly predicted by APOPTO-CELL to achieve appropriate levels of caspase- 3 activation within the $60 \mathrm{~min}$ simulation timeframe, with a median time of 26 min to achieve $80 \%$ substrate cleavage (Figure 3a). Of the cell lines, which failed to respond to $\mathrm{TMZ}$ in vitro, $83 \%$ also failed to reach sufficient substrate cleavage within the simulation time of $60 \mathrm{~min}$ (Figure $3 b$ ). The time calculated by APOPTO-CELL to achieve sufficient levels of caspase-3 activation for efficient execution of apoptosis varied significantly between the TMZ sensitive and TMZ tolerant groups of cells (log-rank, $P=0.0007$; Figure 3c).

We also undertook an examination of the methylation status of the promoter region of the DNA-repair enzyme, 
a

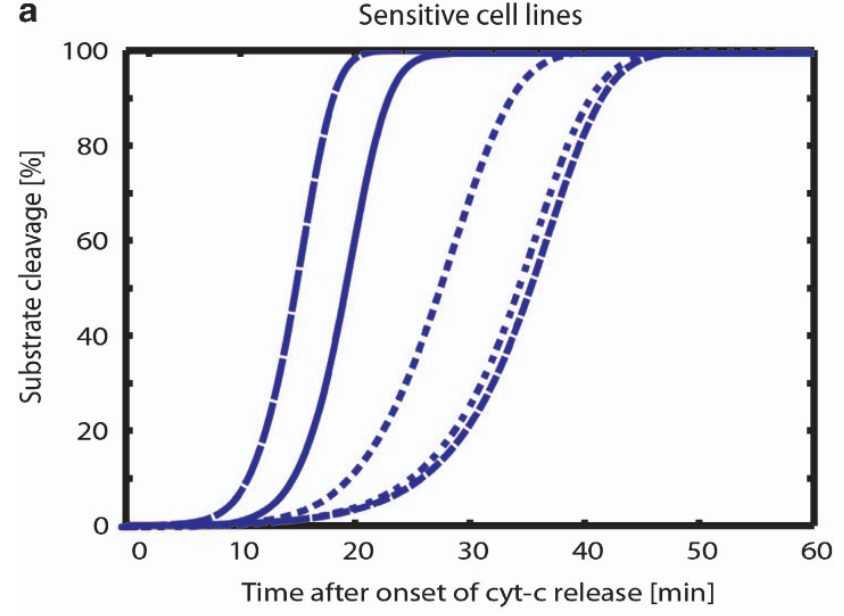

b
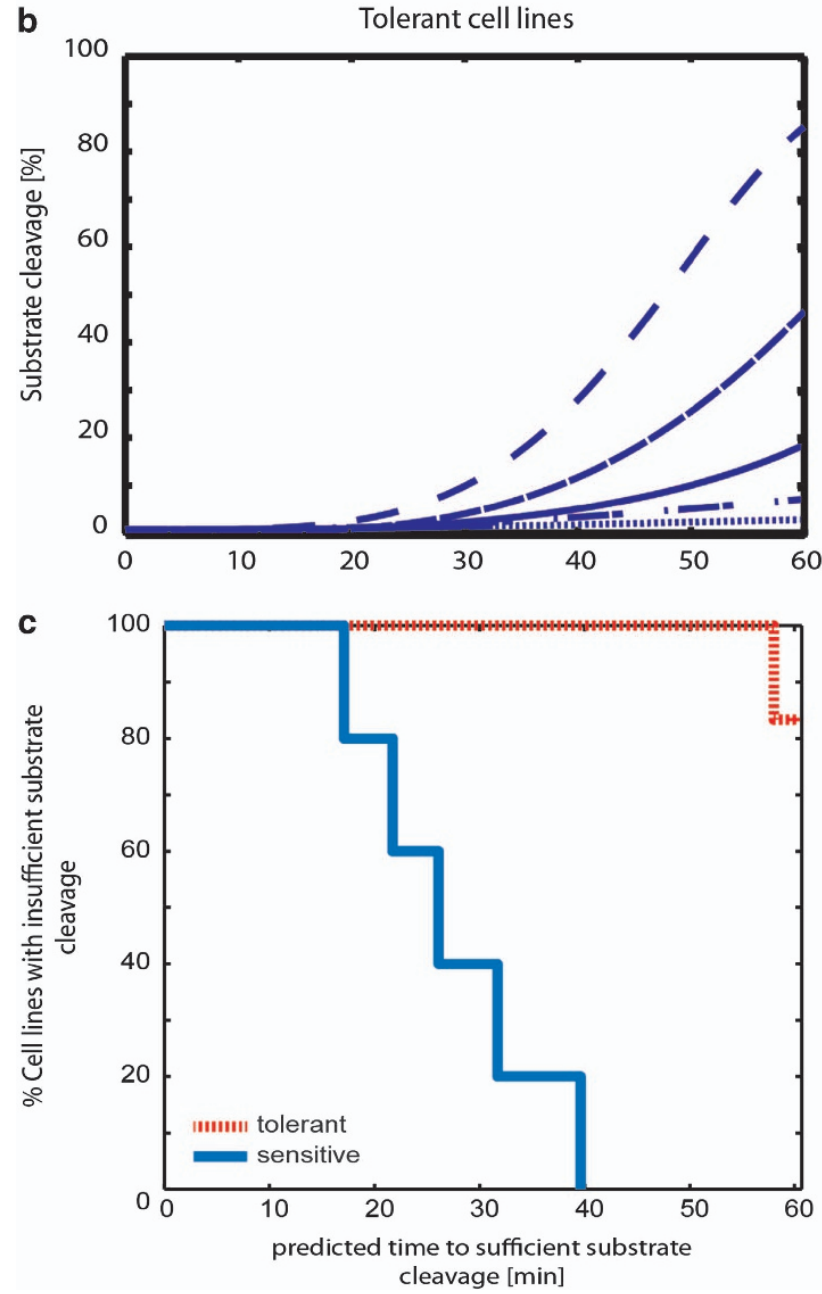

Figure 3 The APOPTO-CELL outputs for TMZ tolerant and sensitive GBM cell lines. The calculated protein expression levels of procaspase-3, Apaf-1, procaspase-9, Smac and XIAP in the 11 GBM cell lines were used as input for the APOPTO-CELL model software. The time ( $\mathrm{min}$ ) taken to achieve $80 \%$ caspase-3 substrate cleavage after cytochrome $c$ release was calculated for the TMZ tolerant (a) and TMZ sensitive GBM cell lines (b). Kaplan-Meier curve showing that the predicted times to $80 \%$ caspase- 3 substrate cleavage vary significantly between TMZ tolerant and sensitive cell lines ((c); log-rank $P=0.0007)$
$\mathrm{O}^{6}$-methylguanine-DNA methyltransferase (MGMT) in our cell lines (Table 1), as it has previously been shown that a methylated MGMT promoter is associated with chemosensitivity to TMZ. ${ }^{26-28}$ All sensitive cell lines displayed methylation of their MGMT promoter, explaining their ability to respond to $\mathrm{TMZ}$, but so too did $50 \%$ of the cell lines, which were unresponsive to the drug (Table 1), giving an overall predictive rate of $73 \%$ ( 8 of 11 cell lines). Interestingly, therefore, our systems medicine approach was better able to explain the differing responses of the cell lines to TMZ than analysis of the methylation status of the MGMT promoter (predictive rates of 91 versus $73 \%$, respectively).

Confirming the induction of apoptosis in cell lines predicted by APOPTO-CELL as TMZ-sensitive. It has been reported that $T M Z$ predominantly induces an apoptotic type of cell death in glioma cells. ${ }^{29}$ To verify that the GBM cell lines, predicted by APOPTO-CELL as capable of supporting caspase activation upon appropriate stimulation, were undergoing apoptosis following exposure to $\mathrm{TMZ}$ in vitro, two representative cell lines from the sensitive group, U251 and U343 and two TMZ-tolerant cell lines, MZ294 and MZ304 were selected for further analysis (Figure 4a). Initially, the observed cell death following TMZ treatment was quantified using Hoechst staining (Figure $4 \mathrm{~b}$ ). The loss of viability in the sensitive cell lines was associated with the appearance of pyknotic nuclei and morphological changes characteristic of apoptosis (Figure $4 \mathrm{~b}$; ${ }^{\star} P<0.05$ ). To further examine this mode of cell death, the cells were treated with $T M Z$ in the presence and absence of ZVAD and stained with AnnexinV (Figure 4c). Following treatment, TMZ-sensitive cells were AnnexinV positive in numbers reflective of those achieved by the previous Hoechst staining of drug-treated cells (Figures $4 \mathrm{~b}$ and $\mathrm{c}$ ). The expression of AnnexinV was significantly $(P<0.001)$ but not entirely blocked by zVAD (Figure $4 c)$. In correlation with the results obtained from the MTT viability assay (Figure 1), neither Hoechst nor AnnexinV staining was evident in the treated MZ294 and MZ304 cells (Figures 4b and $c$ ). Apoptotic death of the sensitive lines following TMZ treatment was also supported by the activation of the executioner caspase-3, and cleavage of the caspase substrate PARP in the sensitive cell lines, but not in the TMZ-tolerant lines (Figure 4d). Collectively these data

Table 1 Cell line characteristics

\begin{tabular}{llll}
\hline Cell line & Response to TMZ & $\begin{array}{l}\text { Methylation status } \\
\text { of MGMT promoter }\end{array}$ & p53 status \\
\hline U87 & Sensitive & Methylated & Wild-type $^{42}$ \\
U251 & Sensitive & Methylated & Mutant $^{42}$ \\
U343 & Sensitive & Methylated & Mutant $^{43}$ \\
U373 & Sensitive & Methylated & Mutant $^{42}$ \\
A172 & Sensitive & Methylated & Wild-type \\
MZ-18 & Tolerant & Methylated & Unknown \\
MZ-51 & Tolerant & Methylated & Unknown \\
MZ-256 & Tolerant & Unmethylated & Unknown \\
MZ-294 & Tolerant & Methylated & Unknown \\
MZ-304 & Tolerant & Unmethylated & Unknown \\
MZ-327 & Tolerant & Unmethylated & Unknown \\
& & & \\
\hline
\end{tabular}

Abbreviation: TMZ, temozolomide. 

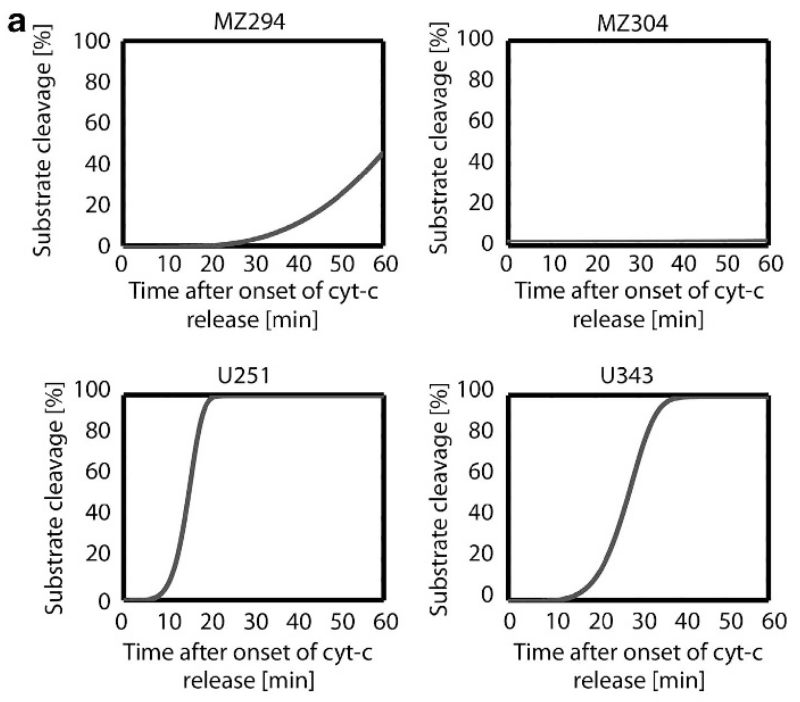

b
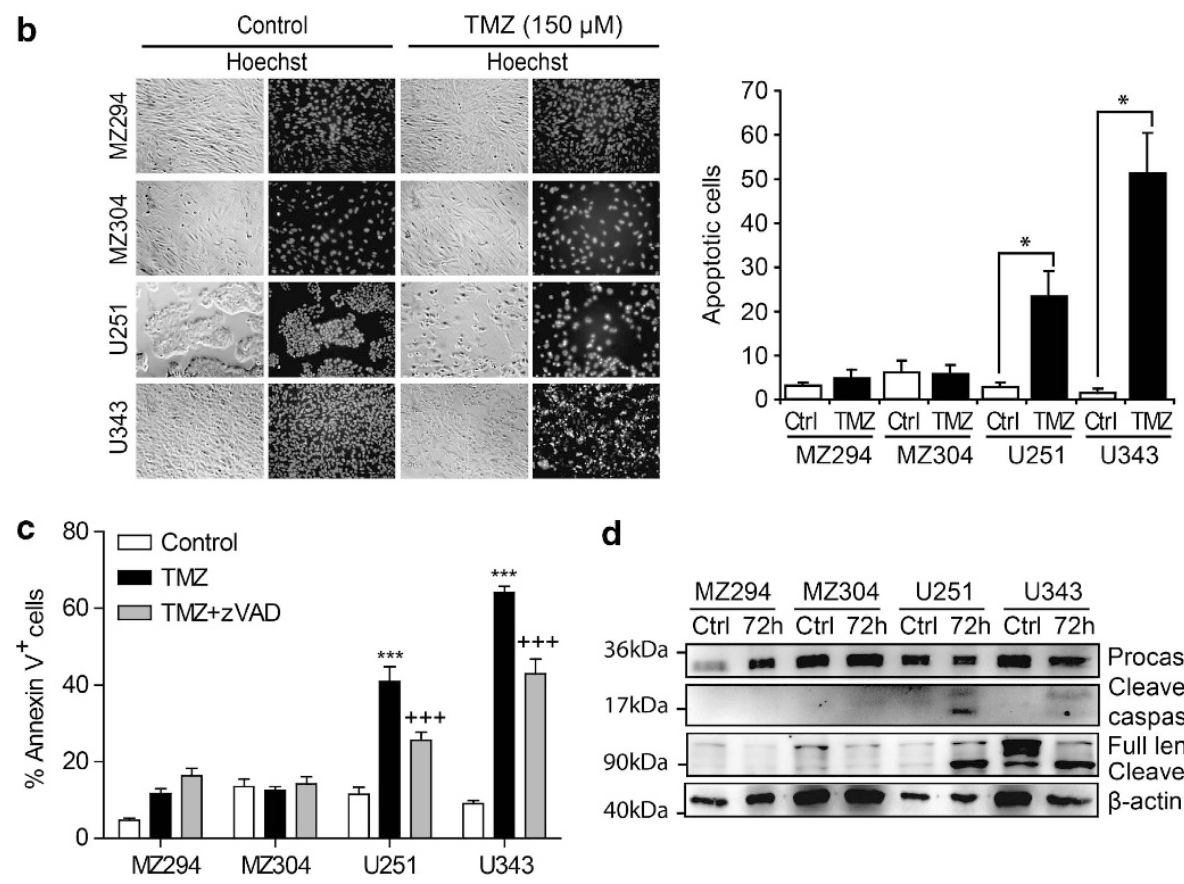

d

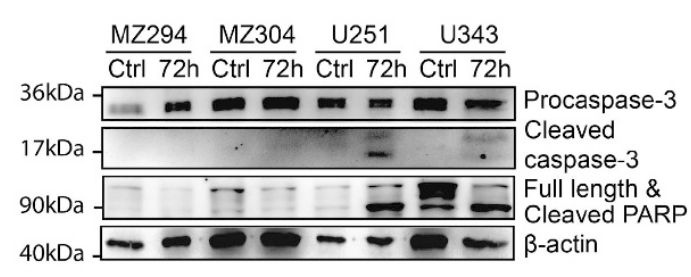

Figure 4 U251 and U343 cells undergo caspase-dependent apoptosis following treatment with TMZ. APOPTO-CELL outputs for two TMZ-tolerant cell lines, MZ294 and MZ304, and two TMZ-sensitive cell lines, U251 and U343 (a). All cell lines were treated with TMZ (150 $\mu \mathrm{M}$ ) for $72 \mathrm{~h}$. TMZ-induced apoptosis was assessed by Hoechst and AnnexinV positive staining and western blot analysis. Brightfield and UV-light images ( $\times 20$ magnification) of TMZ-treated GBM cells following Hoechst staining (b), condensed/fragmented nuclei were considered apoptotic, counted and expressed as a percentage of the total cell number $\left((\mathbf{b}) ;{ }^{*} P<0.05, n=3\right)$. The cell lines were treated with TMZ in the presence or absence of ZVAD for $72 \mathrm{~h}$ and TMZ-induced apoptosis was determined by AnnexinV positive staining using flow cytometry $\left((\mathbf{c}) ;{ }^{* \star \star} P<0.001\right.$; versus control treated cells, ${ }^{++}+P<0.001$; versus TMZ-treated cells). Data are expressed as mean \pm S.E.M. from three independent experiments. Western blot analysis of the protein expression levels of procaspase-3, cleaved caspase-3, PARP and cleaved PARP in the cell lines following TMZ treatment for $72 \mathrm{~h}$ (d)

(Figures $4 b-d)$ provide strong support for the role of the intrinsic apoptotic pathway as a critical mediator of cell death elicited by TMZ within the sensitive GBM cell lines. Although not a focus of this study, other forms of cell death may also make a contribution, however.

Application of the systems model, APOPTO-CELL determines PFS of GBM patients. Having identified the potential use of a systems biology approach to predict the response of GBM cell lines to treatment, we hypothesized that this approach could be applied in a clinical setting to predict patient responses to therapy. Therefore, we analysed tumor resections isolated from 21 GBM patients by quantitative western blotting, ${ }^{22}$ to determine the levels of the proapoptotic proteins Apaf-1, procaspase-3, procaspase- 9 and Smac and the antiapoptotic protein XIAP (Figure 5). The expression of Apaf-1 was comparable to the HeLa control (Figure 5a). Examination of the data showed significantly greater expression of procaspase-3 in certain GBM patient samples compared with others and when compared with the 
a
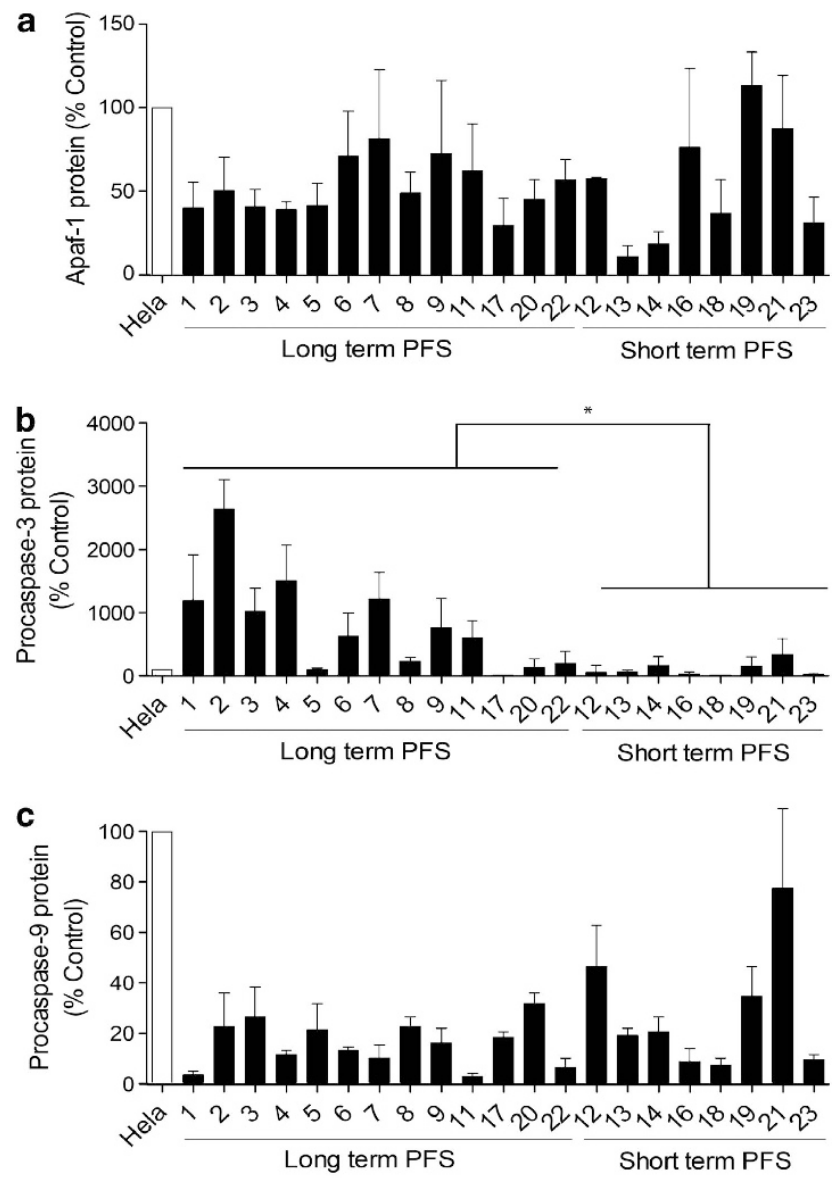

\section{d}

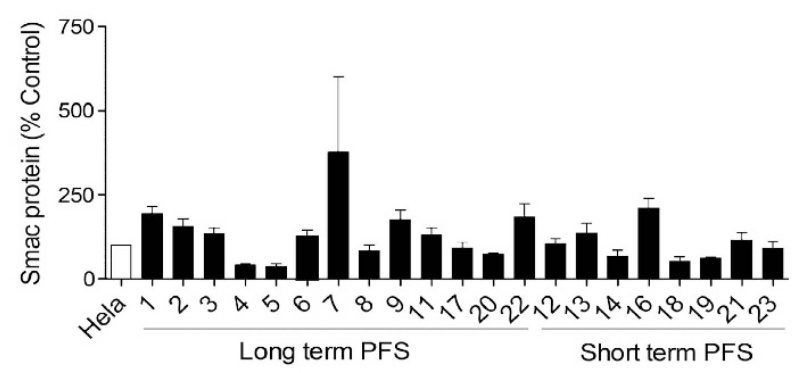

e

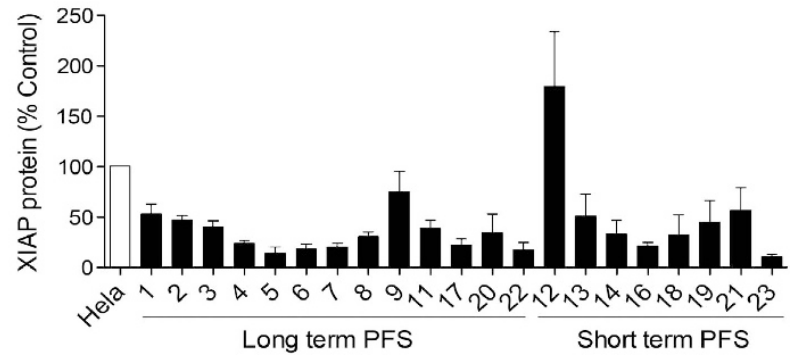

Figure 5 Determination of apoptosis-associated protein concentrations in resections from GBM patients. The patient samples were grouped according to their PFS times. Those with PFS times of $>7$ months were defined as long-term while those with PFS times of $<7$ months were defined as short-term. The concentrations of Apaf-1 (a), procaspase-3; Mann-Whitney U-test, ${ }^{\star} P<0.05$ (b), procaspase-9 (c), Smac (d) and XIAP (e) were determined in resections from GBM patients by western blotting and densitometry. These concentrations were compared with a HeLa standard control (white bar), data expressed as mean \pm SEM for 3 independent experiments
HeLa standard (Figure 5b). In contrast and consistent with the findings in cell lines, levels of procaspase- 9 in all GBM resections were consistently lower than the HeLa standard control (Figure 5c). Differential expression of Smac and XIAP was observed in the patient samples with the majority of samples expressing greater levels of Smac (Figure 5d) but lower levels of XIAP expression compared with the HeLa control (Figure 5e). A statistical analysis of these protein expression levels relative to patient PFS times (Table 2), indicated significantly higher expression of procaspase-3 in the patients with longer PFS times ( $>7$ months) than in those individuals with shorter PFS times ( $<7$ months; Mann-Whitney U-test; $P=0.004$ ). No significant differences were identified in the expression of Apaf-1 $(P=0.59)$, procaspase-9 $(P=0.34)$, XIAP $(P=0.86)$ and Smac $(P=0.051)$.

Next, using the calculated concentrations of the apoptosisrelated family of proteins as input (Table 3B; Supplementary Material), the APOPTO-CELL model was used to determine the susceptibility towards caspase activation for each patient. Figure 6a shows the APOPTO-CELL predictions for those patients surviving 7 months or longer without tumor reoccurrence and all were predicted to be capable of supporting executioner caspase activation (Figure 6a). Of the eight patients who had suffered tumor reoccurrence within 7 months, three were also accurately predicted by APOPTO-CELL as being incapable of activating sufficient levels of executioner caspases (Figure 6b). Analysis of the data showed that the predicted time to achieve $80 \%$ substrate cleavage was significantly shorter for patients with longer PFS times than for those patients whose tumors had reoccurred within the same timeframe $(6.3 \mathrm{~min}$ versus $24.6 \mathrm{~min}$, log-rank test, $P=0.0047$; Figure $6 \mathrm{c}$ ). Overall, the APOPTO-CELL model had a predicative rate of $76.2 \%$ as the model's substrate cleavage profiles correlated with PFS times in 16 of the 21 patients analysed.

We also undertook an analysis of the methylation status of the MGMT promoter within the patient tumor samples (Table 2). Amongst the patients with short PFS times ( $<7$ months), six had unmethylated promoters and the remaining two had inconclusive results despite repeated analysis. For patients with longer PFS times ( $>7$ months), five expressed a methylated promoter and five expressed an unmethylated promoter. Three samples were again inconclusive. Regarding patients with short PFS times, the MGMT promoter methylation analysis had a greater predictive rate $(100 \%(6 / 6)$ versus $37.5 \%(3 / 8))$, while for those patients with longer PFS times, the APOPTO-CELL model was more accurate $(40 \%(4 / 10)$ versus $100 \%(13 / 13))$, indicating perhaps that when apoptosis can occur in a system, the APOPTO-CELL model is better able to predict overall outcome. Taking both patient populations into consideration and excluding those with unknown status of their MGMT promoter, the APOPTO-CELL model was more accurate as a predictive determinant of patient PFS times $(62.5 \%(10 / 16)$ versus $81.25 \%(13 / 16)$ ). However, given the limited number of patient-derived samples and the retrospective analysis of clinical data that were accessible for this study, this result will need to be validated independently and in a larger clinical cohort. 
Table 2 Patient clinical characteristics

\begin{tabular}{|c|c|c|c|c|c|c|c|c|c|}
\hline $\begin{array}{l}\text { Patient } \\
\text { number }\end{array}$ & $\begin{array}{l}\text { Tumor } \\
\text { entity }\end{array}$ & Age & Sex & KPS & $\begin{array}{l}\text { Treatment } \\
\text { strategy before } \\
\text { resection }\end{array}$ & $\begin{array}{l}\text { Steroid } \\
\text { use }\end{array}$ & Dose reduction & PFS (months) & $\begin{array}{l}\text { Methylation } \\
\text { status of } \\
\text { MGMT promoter }\end{array}$ \\
\hline 1 & GBM & 48 & $\mathrm{~F}$ & 100 & None & No & No & 17.2 & Unmethylated \\
\hline 2 & GBM & 59 & $\mathrm{~F}$ & 90 & None & No & No & 16.8 & Unknown \\
\hline 3 & GBM & 22 & $\mathrm{~F}$ & 100 & None & No & No & Ltf after 46.5 & Unmethylated \\
\hline 4 & GBM & 42 & $\mathrm{~F}$ & 90 & None & No & No & 21.5 & Methylated \\
\hline 5 & GBM & 68 & $M$ & 30 & None & No & Unknown & Ltf after 10 & Unmethylated \\
\hline 6 & GBM & 66 & $M$ & 80 & None & Yes & No & 11.1 & Unknown \\
\hline 7 & GBM & 71 & $\mathrm{~F}$ & 70 & None & No & No & 16.1 & Unmethylated \\
\hline 8 & $\begin{array}{l}\text { GBM, } \\
\text { recurrence }\end{array}$ & 70 & $\mathrm{~F}$ & 80 & None & No & Unknown & Ltf after 10 & Methylated \\
\hline 9 & GBM & 59 & $\mathrm{~F}$ & 80 & None & No & $\begin{array}{c}\text { Yes } \\
\text { (thrombocytopenia) }\end{array}$ & 8.4 & Unknown \\
\hline 11 & GBM & 59 & $M$ & 70 & None & No & No & 7.4 & Unmethylated \\
\hline 12 & GBM & 61 & M & 70 & None & No & No & 2.6 & Unmethylated \\
\hline 13 & GBM & 44 & M & 90 & None & No & No & 6.1 & Unmethylated \\
\hline 14 & GBM & 55 & $\mathrm{~F}$ & 70 & None & No & No & 5.4 & Unknown \\
\hline 16 & GBM & 67 & $M$ & 70 & None & Yes & No & 3.7 & Unmethylated \\
\hline 17 & GBM & 64 & $\mathrm{~F}$ & 60 & None & Yes & No & 8.9 & Methylated \\
\hline 18 & $\begin{array}{l}\text { GBM, } \\
\text { recurrence }\end{array}$ & 53 & $\mathrm{~F}$ & 70 & $\begin{array}{l}\text { Combined radiotherapy } \\
\text { and } \mathrm{TMZ} \text {-therapy before } \\
\text { resection }\end{array}$ & No & Yes (pancytopenia) & 6.9 & Unmethylated \\
\hline 19 & $\begin{array}{l}\text { GBM, } \\
\text { recurrence }\end{array}$ & 66 & M & 80 & $\begin{array}{l}\text { Combined radiotherapy } \\
\text { and TMZ-therapy before } \\
\text { resection }\end{array}$ & No & No & 2.7 & Unmethylated \\
\hline 20 & GBM & 66 & M & 90 & None & No & No & 7.3 & Unmethylated \\
\hline 21 & GBM & 55 & $\mathrm{~F}$ & 90 & None & No & No & 3.3 & Unknown \\
\hline 22 & GBM & 53 & $\mathrm{~F}$ & 60 & None & No & No & 7.5 & Methylated \\
\hline 23 & $\begin{array}{l}\text { GBM, } \\
\text { recurrence }\end{array}$ & 55 & $\mathrm{~F}$ & 90 & $\begin{array}{l}\text { Combined radiotherapy } \\
\text { and TMZ-therapy before } \\
\text { resection }\end{array}$ & Yes & No & 2.3 & Unmethylated \\
\hline
\end{tabular}

Abbreviations: GBM, glioblastoma, MGMT, O6 -methylguanine-DNA methyltransferase; PFS, progression-free survival; KPS, karnofsky performance score; Ltf, lost to follow up.

\section{Discussion}

This study highlights the potential use of a systems medicine approach in determining PFS in GBM patients. We have validated our previous systems biology approach, ${ }^{22,23}$ and demonstrated that determining the interaction between apoptosis-associated proteins, namely Apaf-1, procaspase-3, procaspase-9, Smac and XIAP, can predict the susceptibility of GBM cell lines to undergo apoptosis following treatment with TMZ. Importantly, analysis of the simulated interplay between quantitatively determined expression levels of these proteins in resected tumor patient samples allowed for the retrospective stratification of GBM patients with long or shortterm PFS times, $>7$ months and $<7$ months, respectively, thus delivering a unique and novel prognostic tool.

This study collectively assessed the basal levels of Apaf-1, procaspase-3, procaspase- 9 , Smac and XIAP in GBM patient samples and a panel of human cell lines. Establishing the basal levels of these apoptotic proteins within GBMs is essential as it determines if these tumor cells have the molecular machinery necessary to undergo apoptosis following MOMP. After the release of cytochrome $c$ from the mitochondria, it binds Apaf-1 resulting in the recruitment of procaspase- 9 and formation of the apoptosome. ${ }^{13}$ We have shown that all patient samples and GBM cell lines express these proteins and therefore, in theory, have the ability to undergo apoptosis following MOMP. However, we observed low-levels of procaspase-9 in GBM patient samples and low-levels of procaspase- 9 and Apaf- 1 in the GBM cell lines, when compared with the HeLa control. It has previously been published that HeLa cell lines express levels of procaspase- 9 that are similar to other cancer cell lines and its levels of Apaf1 are lower than other cancer cell lines. ${ }^{22}$ In contrast to our data, procaspase-9 has previously been shown to be overexpressed in brain tumors. ${ }^{20}$ There is conflicting evidence in the literature as to whether Apaf- 1 is upregulated in $\mathrm{GBM}^{30}$ or downregulated. ${ }^{31}$ Our finding of low-procaspase- 9 expression in GBM patient samples and both low procaspase- 9 and Apaf-1 expression in GBM cell lines may account, in part, for the observed apoptosis resistance in GBM as it could result in reduced apoptosome formation after the release of cytochrome $c$.

Elucidating the basal expression levels of these proteins in GBM allowed us to examine the validity of using these proteins individually as discriminators of patient or cell line response to treatment. XIAP, a member of the IAPs, is known to inhibit apoptosis by binding to caspase- 9 and downstream effector caspases 3 and $7 .^{32}$ Previous studies have shown XIAP to be primarily highly expressed in GBM cell lines and its overexpression associated with poor prognosis. ${ }^{21}$ This study demonstrated predominantly low-levels of XIAP expression in patient samples and varied expression levels in the GBM cell lines and these basal levels did not correlate with the PFS times of GBM patients, nor with the susceptibility of GBM cell lines to undergo apoptosis. Similarly, basal levels of procaspase-9, Apaf-1 or Smac were unable to discriminate between patients with short or long PFS times or GBM cell lines that were sensitive or tolerant to treatment with TMZ. Interestingly, 
differential expression of procaspase-3 was observed in the GBM patient samples and in the GBM cell lines, and was found to correlate with TMZ sensitivity in the cell lines and PFS
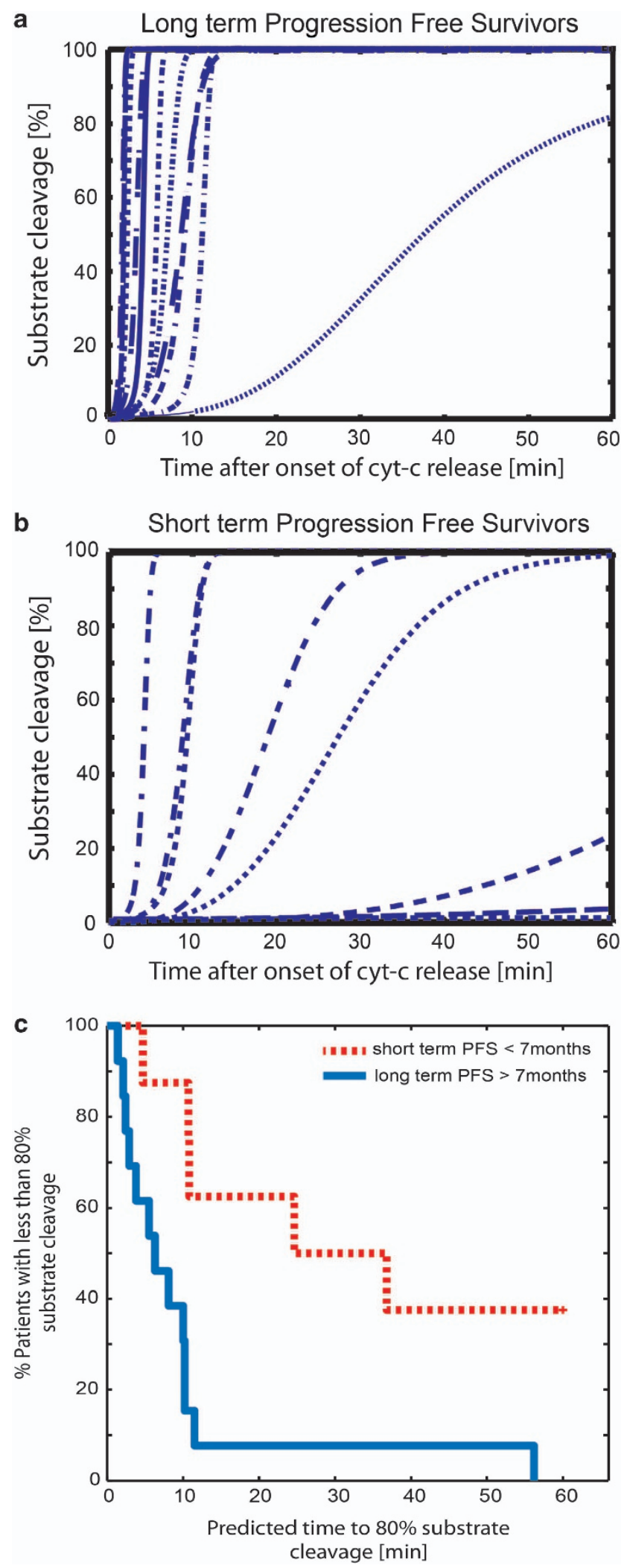

times in patients. High-expression levels of active caspase-3 have been previously shown to be associated with an apoptotic phenotype of cells in GBM patient samples, ${ }^{33}$ and therefore our data suggest that longer PFS times in patients may be associated with a higher rate of apoptosis within the tumors. Of note, three patients were exposed to chemoradiation before surgery, and it cannot be excluded that this may have resulted in the altered expression levels of the apoptotic proteins examined for these individuals. In future, more comprehensive studies are required to investigate this caveat further.

However, the use of a statistical test as a method of stratifying patients into those likely to respond best to apoptosis-inducing therapies requires a large cohort of patient data to be statistically meaningful and, most crucially, is less able to predict how patients may respond to new therapeutics that interfere with this signaling pathway. Our systems biology approach, APOPTO-CELL, overcomes this obstacle by analyzing the dynamic interactions of five key apoptotic proteins in an individual patient sample. This method may become highly relevant in the clinical setting, as it may allow for a redefinition of clinical phenotypes, and a stratification of patients who may respond and may not respond to radio/ chemotherapy, or who may benefit from novel chemotherapeutics such as Smac mimetics/IAP antagonists. TMZ is the current standard chemotherapeutic drug for GBM patients. ${ }^{3,4}$ To date, the only significant predictive marker of GBM patient response to $T M Z$ is the DNA repair enzyme MGMT. Patients with MGMT promoter methylation have a much better prognosis with $\mathrm{TMZ}$ than those without it. ${ }^{27,28}$ We too observed that the tumors isolated from our patient cohort with short PFS times all expressed unmethylated MGMT promoters. However, due to the lack of alternative therapeutic strategies for patients and the fact that even patients without MGMT promoter methylation can respond to treatment with $\mathrm{TMZ},{ }^{26}$ as was also highlighted by our methylation analysis of MGMT promoter amongst the patient cohort with longer PFS times, this biomarker analysis has no direct influence on treatment strategy options for the clinician. Regardless of MGMT promoter methylation status, the prognosis for GBM remains dismal, with the median survival rate for patients with these highly aggressive brain tumors being 12 months. ${ }^{4,34}$ As a result, new treatment paradigms are continually being explored. Targeting IAPs to release caspases and stimulate apoptosis is being investigated for various cancers, with some IAP-targeting drugs currently in preclinical trials. ${ }^{35}$ Interestingly, targeting XIAP through gene transfer of Smac or exposure to Smac peptides has been shown to sensitize GBM cells in vitro and in vivo to apoptosis induced by tumor necrosis factor-related apoptosis-inducing ligand (TRAIL) ${ }^{36}$

Figure 6 APOPTO-CELL outputs of resections from GBM patients. Concentrations of Apaf-1, procaspase-3, procaspase-9, Smac, and XIAP in GBM patient resections were entered into the APOPTO-CELL software. The time to $80 \%$ substrate cleavage following cytochrome $c$ release was calculated for each sample. APOPTO-CELL outputs for long-term progression-free survivors (a) and for shortterm progression-free survivors (b). Kaplan-Meier curve showing that the predicted times to $80 \%$ caspase- 3 substrate cleavage are significantly shorter for patients with long-term PFS times compared with patients with short-term PFS times ((c); median $6.3 \mathrm{~min}$ versus $24.6 \mathrm{~min}$, log-rank test, $P=0.0047$ ) 
and by $\gamma$-irradiation. ${ }^{37}$ In GBM, where a decrease in apoptosome components may contribute to drug resistance, it may also prove beneficial to trial agents that increase the expression of apoptosome components Apaf-1 and procaspase-9, for example, by utilizing the pan-histone deacetylase inhibitor LAQ824. ${ }^{38}$ Thus, APOPTO-CELL may be a useful tool for classifying patients who will benefit from these novel therapies that target the intrinsic apoptotic pathway and may in the future help oncologists make better informed treatment decisions.

In conclusion, few if any studies have examined the combination of these apoptosis-associated proteins or indeed taken into consideration their possible interactions, when investigating potential treatment outcomes. Consequently, our analysis incorporating the interactions amongst these proteins represents a novel strategy for predicting patient outcome in GBM. Considering the wealth of strategies targeting apoptosis in GBM currently in clinical trials, ${ }^{39,40}$ this systems medicine approach for determining GBM therapeutic response not only has validity for today's patients but also will be highly valuable in the future treatment of GBM.

\section{Materials and Methods}

GBM cell lines. The commercially available GBM cell lines A172, U87, U251, U343 and U373, as well as the established GBM cell lines MZ-18, MZ-51, MZ-294, MZ-304, MZ-327 and MZ256 were kindly donated by Prof Donat Kögel of Johann Wolfgang Goethe University Hospital, Frankfurt, Germany. The characterization of the commercially available cell lines is available from the American Type Culture Collection and the newly established cell lines have previously been characterized by immunostaining. ${ }^{24}$ The cells were grown in DMEM with $10 \%$ heat-inactivated fetal calf serum, $100 \mathrm{U} / \mathrm{ml}$ penicillin and $100 \mathrm{mg} / \mathrm{ml}$ streptomycin and were maintained in a humidified incubator at $37^{\circ} \mathrm{C}$ and $5 \% \mathrm{CO}_{2}$. HeLa cells were grown and maintained under the same conditions.

MTT assay. The GBM cell lines were plated in 96-well plates (500-2000 cells/ well), treated with TMZ $(150 \mu \mathrm{M})$ and a cell viability assay was carried out $24,48,72$, 96 and $120 \mathrm{~h}$ post-treatment. Following treatment, thiazolyl blue tetrazolium bromide (MTT, $5 \mathrm{mg} / \mathrm{ml}$; Sigma Aldrich, Dublin, Ireland) was added to each well and incubated in the dark at $37^{\circ} \mathrm{C}$. MTT produces a yellowish solution that is converted to dark blue, water-insoluble MTT formazan by mitochondrial dehydrogenases of living cells. After $4 \mathrm{~h}$, the medium was aspirated and the dark blue crystals were dissolved in DMSO $(200 \mu \mathrm{l})$. The absorbance of each sample was measured at $560 \mathrm{~nm}$ using a microplate reader (GENios, Tecan, Mannedorf, Switzerland). The absorbance was considered proportional to the number of viable cells.

Patient samples. Patient samples were obtained from the tumor tissue bank at the University Cancer Centre, Frankfurt (Table 2). Their use was approved by the local ethics committee of the Frankfurt University Hospital. These resections were removed from patients before treatment with radiotherapy and TMZ chemotherapy except for patients 18,19 and 23. PFS time is defined as the period of time between surgical removal of the tumor and subsequent tumor regrowth. For classification purposes, any patient who had a PFS time of greater than 7 months was classified a long-term progression-free survivor and any patient who had a PFS time of less than 7 months was classified a short-term progression-free survivor. This stratification enabled an optimum number of patients $(n)$ in each group (long-term PFS, $n=13$; short term PFS, $n=8$; Table 2) for meaningful statistical analysis.

MGMT promoter methylation status assessed by methylationspecific PCR (MSP). Tumor specimens showing the largest amount of vital tumor tissue (goal: $>70 \%$ vital tumor tissue) were selected for MSP. Four slides of $10-\mu \mathrm{m}$ thickness were cut from each paraffin block. Slides were deparaffinized using xylene and $2 \times 96 \%$ alcohol. DNA-Isolation was performed using DNeasy Blood \& Tissue Kit (Qiagen, Hilden, Germany). DNA was isolated from the cell lines using QIAamp DNA Mini Kit (Qiagen). Nucleic acid concentration was determined by UV spectrophotometric analysis using Nanodrop 1000 Spectrophotometer.
DNA was treated with sodium bisulfite using the EZ DNA Methylation-Gold Kit (Zymo Research, ORT, New York, NY, USA). PCR run was performed on the Thermocycler T3000 (Biometra, Gottingen, Germany). For PCR, $2 \mu \mathrm{l}$ of sodium bisulfite-pretreated DNA was amplified by the following primer sets:

(I) MGMT-methylated forward primer: 5'-GTTTTTAGAACGTTTTGCGTTT CGAC-3'; (II) MGMT-methylated reverse primer: $5^{\prime}$-CACCGTCCCGAAAAAAACT CCG-3';

(III) MGMT-unmethylated forward primer: 5'-TGTGTTTTTAGAATGTTTTGTGTT TTGAT-3';

(IV) MGMT-unmethylated reverse primer: 5'-CTACCACCATCCCAAAAAAAAAC TCCA-3'. DNA from the glioma cell line LNT229 was used as positive control for a methylated MGMT promoter and DNA from healthy volunteer donors were used as positive control for an unmethylated MGMT promoter status. Water was used as negative control in each MSP run. After MSP, $20 \mu \mathrm{l}$ of each sample was loaded on a $2 \%$ agarose-gel at $120 \mathrm{~V}$ for $35 \mathrm{~min}$.

Hoechst staining of nuclear chromatin. Hoechst staining was performed on both untreated control cells and cells treated with TMZ $(150 \mu \mathrm{m})$ for $72 \mathrm{~h}$. Cells were stained with Hoechst $33258(1 \mu \mathrm{g} / \mathrm{ml}$; Sigma Aldrich), incubated for $10 \mathrm{~min}$ at $37^{\circ} \mathrm{C}$ and nuclear morphology was visualized using an Eclipse TE 300 inverted microscope (Nikon, Düsseldorf, Germany) using a $20 \times$ objective. A minimum of 300 cells were counted in three subfields of each culture. Those cells with condensed/fragmented nuclei were deemed apoptotic, counted (using ImageJ software, National Institute of Mental Health, Bethesda, MD, USA) and expressed as a percentage of total cell number.

Western blot analysis. Resected tumor tissue from GBM patients and GBM cell lines were homogenized in lysis buffer containing $0.5 \mathrm{mmol} / / \mathrm{Tris}-\mathrm{HCl}(\mathrm{pH} 6.8)$, $2 \%$ SDS (w/v), $10 \%$ glycerin (w/v) and protease and phosphatase inhibitor cocktails (Sigma Aldrich). After determining the protein concentration of the samples using a BCA protein assay (Pierce, Rockford, IL, USA), $20 \mu \mathrm{g}$ samples were boiled in gel-loading buffer and separated on 10-15\% SDS-PAGE gels. Proteins were transferred to nitrocellulose membranes using the iBlot gel transfer device (Life Technologies, Invitrogen, Paisley, Scotland). The membranes were incubated with the following antibodies: Smac, caspase-3, caspase-9 (Cell signalling Technology, Beverly, MA, USA), XIAP (BD Biosciences, Oxford, UK) and Apaf-1 (Chemicon, Hampshire, UK). For the GBM cell lines treated with TMZ $(150 \mu \mathrm{m})$ for $72 \mathrm{~h}$, the membranes were incubated with antibodies against caspase-3, cleaved caspase-3, PARP and cleaved PARP (Cell signalling Technology). Membranes were next incubated with horseradish peroxidaseconjugated secondary antibodies (Jackson ImmunoResearch, Plymouth, PA, USA) and protein bands were visualized using Supersignal West Pico Chemiluminescent Substrate (Pierce). Images were captured using a LAS-3000 Imager equipped with a cooled 12 bit digital CCD camera (FUJIFILM UK Ltd Systems, Sheffield, UK).

For quantitative western blotting, standard curves from HeLa cell extracts $(5-20 \mu \mathrm{g})$ were run concurrently with the GBM cell line and patient lysates $(20 \mu \mathrm{g})$ to ensure linearity of the signal detection range. The protein concentrations of Apaf-1, procaspase-9, procaspase-3, Smac and XIAP within each GBM cell line and individual GBM patient resected tumor sample were determined by comparison to signals from HeLa cell extracts (Table 3; Supplementary Material). The concentrations of each protein in HeLa cells were previously determined and adapted from Rehm et al., ${ }^{22}$ Special care was taken not to overexpose any pixels to guarantee accurate quantifications. Digital densitometry was performed using ImageJ software after background subtraction by quantifying signal intensities of the chemiluminescence signals and normalized to $\beta$-actin. For all proteins at least three detections were evaluated. Data are expressed as mean \pm S.E.M.

Flow cytometry. MZ-294, MZ304, U251 and U343 cell were pretreated with ZVAD $(50 \mu \mathrm{m})$ for $30 \mathrm{~min}$ and then treated with TMZ $(150 \mu \mathrm{M})$ for $72 \mathrm{~h}$. Following treatment, monolayer cells were harvested with trypsin-EDTA and washed with PBS. Cells were then incubated at room temperature in binding buffer $(10 \mathrm{~mm}$ HEPES, $135 \mathrm{~mm} \mathrm{NaCl}, 5 \mathrm{~mm} \mathrm{CaCl}$ ), which contained an AnnexinV-FITC conjugate $(1 \mu \mathrm{l} / \mathrm{ml}$; BioVision, Mountain View, CA, USA) for $15 \mathrm{~min}$. Cells were counted in a BD LSR II flow cytometer (BD Biosciences). Excitation of AnnexinV-FITC was done with a $488 \mathrm{~nm}$ laser and fluorescence emission was collected in the FL1 channel through a $520 \mathrm{~nm}$ band pass filter. A total of $1 \times 10^{4}$ gated cells were acquired for each sample and analysed using the Flowmax software (Partec, Munster, Germany). 
Mathematical modeling of apoptosis execution. The model used is the biochemical reactions network, APOPTO-CELL, previously published. ${ }^{22,23}$ This model is based on a set of ordinary differential equations representing a reaction network of 53 reactions, 19 reaction partners and 75 reaction parameters and is implemented in MATLAB. The model was developed in HeLa cells and validated in cellulo and by adapting the model to cancer cell lines deficient in apoptosis signaling proteins. 22,41 The reaction network is initiated by cytochrome c-dependent apoptosome formation and mitochondrial Smac release while substrate cleavage by effector caspases is the model output. ${ }^{23}$ To generate substrate cleavage profiles for the GBM cell lines and GBM patient samples, protein expression values for procaspases- 9 and -3 , XIAP, Smac and Apaf- 1 , as determined by quantitative western blotting for each individual patient sample and cell line, were used as input for APOPTO-CELL and modeled over $60 \mathrm{~min}$. At 60 min varied substrate cleavage profiles were predicted, ranging from $<1$ to $100 \%$. Apoptosis susceptibility in GBM tumor resections and GBM cell lines was defined as the ability to efficiently generate $>80 \%$ substrate cleavage within this 60 min timeframe. A $>80 \%$ substrate cleavage was chosen as it has previously been determined that this \% enables apoptosis to proceed efficiently. ${ }^{22}$

Statistical analysis. Student's t-test was used to analyse the response to TMZ in the cell lines. Mann-Whitney U-tests were performed to identify significant differences in protein expression relative to $\beta$-actin between TMZ sensitive and resistant cell lines and between GBM patient long- and short-term PFS times. To compare the censored times to sufficient caspase activation predicted by systems modeling between TMZ sensitive and resistant cell lines after apoptosis inducing treatment and between patients having long- and short-term PFS, we used logrank tests on the Kaplan-Meier plots. A $P$-value of $<0.05$ was considered to be statistically significant.

\section{Conflict of Interest}

The authors declare no conflict of interest.

Acknowledgements. We would like to express our sincere thanks to the patients who kindly agreed to donate their tissue for this study. This research was generously supported by grants from the Health Research Board (RP/2008/69) and the RCSI Research Committee (GR 08-0155) to BMM, the Health Research Board (RP/2008/7) to MR, Science Foundation Ireland grants 08/INV1/1949 and 07/SK/ B1243a to JHMP and Deutsche Krebshilfe (Grant 108795) to DK.

1. Louis DN, Ohgaki H, Wiestler OD, Cavenee WK, Burger PC, Jouvet A et al. The 2007 WHO classification of tumours of the central nervous system. Acta Neuropathol 2007; 114: 97-109.

2. Maher EA, Furnari FB, Bachoo RM, Rowitch DH, Louis DN, Cavenee WK et al. Malignant glioma: genetics and biology of a grave matter. Genes Dev 2001; 15: 1311-1333.

3. Stupp R, Mason WP, van den Bent MJ, Weller M, Fisher B, Taphoorn MJ et al. Radiotherapy plus concomitant and adjuvant temozolomide for glioblastoma. N Engl J Med 2005; 352: 987-996.

4. Stupp R, Hegi ME, Mason WP, van den Bent MJ, Taphoorn MJ, Janzer RC et al. Effects of radiotherapy with concomitant and adjuvant temozolomide versus radiotherapy alone on survival in glioblastoma in a randomised phase III study: 5-year analysis of the EORTCNCIC trial. Lancet Oncol 2009; 10: 459-466.

5. Ohgaki H, Kleihues P. Population-based studies on incidence, survival rates, and genetic alterations in astrocytic and oligodendroglial gliomas. J Neuropathol Exp Neurol 2005; 64 : 479-489.

6. Krakstad C, Chekenya M. Survival signalling and apoptosis resistance in glioblastomas: opportunities for targeted therapeutics. Mol Cancer 2010; 9: 135.

7. Ziegler DS, Kung AL, Kieran MW. Anti-apoptosis mechanisms in malignant gliomas. J Clin Oncol 2008; 26: 493-500.

8. Stegh AH, Kim H, Bachoo RM, Forloney KL, Zhang J, Schulze H et al. Bcl2L12 inhibits post-mitochondrial apoptosis signaling in glioblastoma. Genes Dev 2007; 21: 98-111.

9. Ruano Y, Mollejo M, Camacho FI, Rodriguez de Lope A, Fiano C, Ribalta T et al. Identification of survival-related genes of the phosphatidylinositol 3 '-kinase signaling pathway in glioblastoma multiforme. Cancer 2008; 112: 1575-1584

10. Strasser A, Cory S, Adams JM. Deciphering the rules of programmed cell death to improve therapy of cancer and other diseases. EMBO J 2011; 30: 3667-3683.

11. Kaufmann SH, Vaux DL. Alterations in the apoptotic machinery and their potential role in anticancer drug resistance. Oncogene 2003; 22: 7414-7430.
12. Zou H, Henzel WJ, Liu X, Lutschg A, Wang X. Apaf-1, a human protein homologous to C. elegans CED-4, participates in cytochrome c-dependent activation of caspase-3. Cell 1997; 90: 405-413.

13. Li P, Nijhawan D, Budihardjo I, Srinivasula SM, Ahmad M, Alnemri ES et al. Cytochrome $c$ and DATP-dependent formation of Apaf- $1 /$ caspase- 9 complex initiates an apoptotic protease cascade. Cell 1997; 91: 479-489.

14. Hu Y, Benedict MA, Ding L, Nunez G. Role of cytochrome $c$ and dATP/ATP hydrolysis in Apaf-1-mediated caspase-9 activation and apoptosis. EMBO J 1999; 18: 3586-3595.

15. Zou H, Li Y, Liu X, Wang X. An APAF-1.cytochrome c multimeric complex is a functional apoptosome that activates procaspase-9. J Biol Chem 1999; 274: 11549-11556.

16. Du C, Fang M, Li Y, Li L, Wang X. Smac, a mitochondrial protein that promotes cytochrome c-dependent caspase activation by eliminating IAP inhibition. Cell 2000; 102: 33-42.

17. Chai J, Du C, Wu JW, Kyin S, Wang X, Shi Y. Structural and biochemical basis of apoptotic activation by Smac/DIABLO. Nature 2000; 406: 855-862.

18. Slee EA, Harte MT, Kluck RM, Wolf BB, Casiano CA, Newmeyer DD et al. Ordering the cytochrome c-initiated caspase cascade: hierarchical activation of caspases-2, -3, -6, -7, -8, and -10 in a caspase-9-dependent manner. J Cell Biol 1999; 144: 281-292.

19. Janicke RU, Sprengart ML, Wati MR, Porter AG. Caspase-3 is required for DNA fragmentation and morphological changes associated with apoptosis. J Biol Chem 1998; 273: 9357-9360.

20. Bodey B, Bodey V, Siegel SE, Nasir A, Coppola D, Hakam A et al. Immunocytochemical detection of members of the caspase cascade of apoptosis in high-grade astrocytomas. In Vivo 2004; 18: 593-602.

21. Wagenknecht B, Glaser T, Naumann U, Kugler S, Isenmann S, Bahr M et al. Expression and biological activity of X-linked inhibitor of apoptosis (XIAP) in human malignant glioma. Cell Death Differ 1999; 6: 370-376.

22. Rehm M, Huber HJ, Dussmann H, Prehn JH. Systems analysis of effector caspase activation and its control by X-linked inhibitor of apoptosis protein. EMBO J 2006; 25 : 4338-4349.

23. Huber HJ, Rehm M, PIchut M, Dussmann H, Prehn JH. APOPTO-CELL-a simulation tool and interactive database for analyzing cellular susceptibility to apoptosis. Bioinformatics 2007; 23: 648-650.

24. Hetschko H, Voss V, Horn S, Seifert V, Prehn JH, Kogel D. Pharmacological inhibition of Bcl-2 family members reactivates TRAIL-induced apoptosis in malignant glioma. J Neurooncol 2008; 86: 265-272.

25. Hammond LA, Eckardt JR, Kuhn JG, Gerson SL, Johnson T, Smith L et al. A randomized phase I and pharmacological trial of sequences of 1,3-bis(2-chloroethyl)-1-nitrosourea and temozolomide in patients with advanced solid neoplasms. Clin Cancer Res 2004; 10: 1645-1656.

26. Hegi ME, Diserens AC, Gorlia T, Hamou MF, de Tribolet N, Weller M et al. MGMT gene silencing and benefit from temozolomide in glioblastoma. N Engl J Med 2005; 352 : 997-1003.

27. Weller M, Felsberg J, Hartmann C, Berger H, Steinbach JP, Schramm J et al. Molecular predictors of progression-free and overall survival in patients with newly diagnosed glioblastoma: a prospective translational study of the German Glioma Network. J Clin Oncol 2009; 27: 5743-5750.

28. Esteller M, Garcia-Foncillas J, Andion E, Goodman SN, Hidalgo OF, Vanaclocha V et al. Inactivation of the DNA-repair gene MGMT and the clinical response of gliomas to alkylating agents. N Engl J Med 2000; 343: 1350-1354.

29. Roos WP, Batista LF, Naumann SC, Wick W, Weller M, Menck CF et al. Apoptosis in malignant glioma cells triggered by the temozolomide-induced DNA lesion O6-methylguanine. Oncogene 2007; 26: 186-197.

30. Johnson CE, Huang YY, Parrish AB, Smith MI, Vaughn AE, Zhang $Q$ et al. Differential Apaf-1 levels allow cytochrome $c$ to induce apoptosis in brain tumors but not in normal neural tissues. Proc Natl Acad SciUSA 2007; 104: 20820-20825.

31. Watanabe T, Hirota Y, Arakawa Y, Fujisawa H, Tachibana O, Hasegawa $M$ et al. Frequent LOH at chromosome 12q22-23 and Apaf-1 inactivation in glioblastoma. Brain Pathol 2003; 13: $431-439$

32. Deveraux QL, Roy N, Stennicke HR, Van Arsdale T, Zhou Q, Srinivasula SM et al. IAPs block apoptotic events induced by caspase- 8 and cytochrome $c$ by direct inhibition of distinct caspases. EMBO J 1998; 17: 2215-2223.

33. Gdynia G, Grund K, Eckert A, Bock BC, Funke B, Macher-Goeppinger S et al. Basal caspase activity promotes migration and invasiveness in glioblastoma cells. $\mathrm{Mol}$ Cancer Res 2007; 5: 1232-1240.

34. Johnson DR, O'Neill BP. Glioblastoma survival in the United States before and during the temozolomide era. J Neurooncol 2011; 107: 359-364.

35. LaCasse EC, Mahoney DJ, Cheung HH, Plenchette S, Baird S, Korneluk RG. IAP-targeted therapies for cancer. Oncogene 2008; 27: 6252-6275.

36. Fulda S, Wick W, Weller M, Debatin KM. Smac agonists sensitize for Apo2L/TRAIL- or anticancer drug-induced apoptosis and induce regression of malignant glioma in vivo. Nat Med 2002; 8: 808-815.

37. Vellanki SH, Grabrucker A, Liebau S, Proepper C, Eramo A, Braun V et al. Small-molecule XIAP inhibitors enhance gamma-irradiation-induced apoptosis in glioblastoma. Neoplasia 2009; 11: 743-752.

38. Wang S, Yan-Neale Y, Cai R, Alimov I, Cohen D. Activation of mitochondrial pathway is crucial for tumor selective induction of apoptosis by LAQ824. Cell Cycle 2006; 5: 1662-1668. 
39. Kogel D, Fulda S, Mittelbronn M. Therapeutic exploitation of apoptosis and autophagy for glioblastoma. Anticancer Agents Med Chem 2010; 10: 438-449.

40. Eisele G, Weller M. Targeting apoptosis pathways in glioblastoma. Cancer Lett 2011; 332 : 335-345.

41. O'Connor CL, Anguissola S, Huber HJ, Dussmann H, Prehn JH, Rehm M. Intracellula signaling dynamics during apoptosis execution in the presence or absence of X-linkedinhibitor-of-apoptosis-protein. Biochim Biophys Acta 2008; 1783: 1903-1913.

42. Mittelbronn M, Platten M, Zeiner P, Dombrowski $\mathrm{Y}$, Frank B, Zachskorn $\mathrm{C}$ et al. Macrophage migration inhibitory factor (MIF) expression in human malignant gliomas contributes to immune escape and tumour progression. Acta Neuropathol 2011; 122 : 353-365.
43. Yin D, Zhou H, Kumagai T, Liu G, Ong JM, Black KL et al. Proteasome inhibitor PS-341 causes cell growth arrest and apoptosis in human glioblastoma multiforme (GBM). Oncogene 2005; 24: 344-354.

cc) (i) $(9)$ Cell Death and Disease is an open-access journal published by Nature Publishing Group. This work is licensed under a Creative Commons Attribution-NonCommercialNoDerivs 3.0 Unported License. To view a copy of this license, visit http://creativecommons.org/licenses/by-nc-nd/3.0/

Supplementary Information accompanies this paper on Cell Death and Disease website (http://www.nature.com/cddis) 